4. Christensen RD, Hill HR, Rothstein 1983 Granulocytic stem cell CFU(c) proliferation in experimental group B streptococcal sepsis. Pediatr Res 17:278

5. Christensen RD. Shigeoka AO. Hill HR, Rothstein G 1980 Circulating and storage neutrophil changes in experimental type Il group B streptococcal sepsis. Pediatr Res 14:806

6. Christensen RD. Bradley PP. Rothstein G 1981 The leukocyte left shift in clinical and experimental group B streptococcal sepsis. J Pediatr 98:101

7. Christensen RD, Bradley PP. Priebat DA, Anstall HB, Rothstein G 1982 Granulocyte transfusion in septic canine neonates. Pediatr Res 16:57

8. Erdman SH. Christensen RD. Bradley PP. Rothstein G 1982 The supply and release of storage neutrophils: a developmental study. Biol Neonat 41:132

9. Grouls V. Helpap B 1980 The granulocytopoiesis in the spleen of newborn rats. Res Exp Med 177:237

10. Lipschitz DA. Udupa KB 1981 The quantitation of the granulocytic/macrophage committed progenitor cell CFU(c) in man and the mouse. Exp Hacmatol 9:723

11. Metcalf D, Moore MAS 1971 Haemopoietic Cells. Amsterdam, North-Holland Publishing Co

12. Miller ME, Raghunathan R. Siegler L 1981 Ontogeny of chemotaxis in ovine polymorphonuclear leukocytes. Clin Res 29:123(A)

13. Playfair JHL. Wolfendale MR. Kay HEM 1963 The leucocytes of peripheral blood in the human foetus. Br J Haematol 9:336
14. Rothstein G Christensen RD Unpublished observations

15. Till JE. McCulloch EA 1980 Hemopoietic stem cell differentiation. Biochim Biophys Acta 605:431

16. Thomas DB. Yoffey JM Human foetal haematopoiesis. I. The cellular composition of foetal blood. Br J Haematol 8:290

17. Usher R Lind J 1965 Blood volume of the newborn premature infant. Acta Paediatr Scan 54:419

18. Wientzen RL, McCracken GH, Jr 1977 Pathogenesis and management of neonatal sepsis and meningitis. In: Current Problems in Pediatrics, vol 8 , p 1

19. Wintrobe MM, Shumacker HB, Jr 1935 Comparison of hematopoiesis in the fetus and during recovery from pernicious anemia. J Clin Invest 14:837

20. Zeligs BJ, Armstrong CD, Walser JB, Bellanti JA 1982 Age-dependent susceptibility of neonatal rats to group B streptococcal type III infection: correlation of severity of infection and response of myeloid pools. Infect Immun 37:255

21. Supported by United States Public Health Service Grant HD-14419 and by grant from the Thrasher Research Fund. Presented in part at the Society for Pediatric Research, Washington, D. C., May, 1983

22. Requests for reprints should be addressed to: Robert D. Christensen, M.D. Division of Hematology, University of Utah School of Medicine, 50 North Medical Drive, Salt Lake City, Utah 84132

23. Received for publication November 16, 1983.

\title{
Increased Regional Myocardial Blood Flows and Oxygen Deliveries during Hypoxemia in Lambs
}

\author{
DAVID J. FISHER ${ }^{(4 i)}$ \\ With the technical assistance of Elizabeth Ott \\ Department of Pediatrics, Medical School, The University of Texas Health Science Center at Houston, \\ Houston, Texas USA
}

Summary

Newborn humans may develop myocardial dysfunction in conjunction with severe birth asphyxia. Subendocardial or papillary muscle ischemia appears to be the basis for the myocardial dysfunction, yet patent coronary arteries have been demonstrated in the nonsurvivors. The asphyxiated newborns also have experienced hypoxemia, which has been suggested as the cause of myocardial ischemia. This study was designed to determine the relationship between reduced aortic blood oxygen content and blood flow as well as oxygen delivery within different regions of the heart. Three days after surgery, we measured blood flow and oxygen delivery to the free walls and papillary muscles of the right and left ventricles, the ventricular septum, and the atria in 10 lambs, during 20 -min periods in $8-10 \%$ and 5-6\% environmental oxygen concentrations. In each region of myocardium, blood flow increased linearly as the aortic blood oxygen content decreased. The slopes of the regression lines were similar for each region of ventricular myocardium. Atrial myocardial blood flow also increased as a linear function of the reductions in aortic blood oxygen content, but at a slower rate than in the ventricular regions. Hypoxemia was associated with increased oxygen delivery in each region of myocardium, but the two variables were not related in a linear or quadratic fashion. The results demonstrate that isolated hypoxemia is associated with increased blood flow and oxygen delivery in the free walls and papillary muscles of the right and left ventricles, the ventricular septum, and the atria.
Several reports have demonstrated that newborn humans may develop regional or global myocardial dysfunction in conjunction with severe birth asphyxia $(6,7,33)$. Subendocardial and/ or papillary muscle ischemia appears to be the basis for the myocardial dysfunction $(4,12,30,33)$. While coronary stenoses are present in most adults who develop myocardial ischemia, there has been no evidence of coronary stenoses in asphyxiated newborns who have expired after developing severe myocardial dysfunction $(4,12,30,33)$. Consequently, the factor(s) that produce myocardial ischemia during birth asphyxia remain to be determined (33).

Several investigators have suggested that the myocardial ischemia of birth asphyxia may be the result of the simultaneous occurrence of hypoxemia, with or without additional stresses such as hypoglycemia $(4,21,30)$. In contrast, our recent work in unanesthetized fetal and newborn lambs has demonstrated that blood flow to the left ventricular free wall increased during hypoxemia $(13,14)$. Since right and/or left ventricular ischemia and dysfunction may occur in asphyxiated human newborns, the present investigation was designed to determine the relationship between hypoxemia and blood flow as well as oxygen delivery within the papillary muscles and free walls of the right and left ventricles, the ventricular septum, and the atria.

\section{MATERIALS AND METHODS}

Surgical technique. Using techniques previously described, we operated on 10 Western newborn lambs 1 to 11 days $(5 \pm 2$, 
mean $\pm \mathrm{SE}$ ) after birth (13). The weight at surgery was $6.3 \pm 0.5$ $\mathrm{kg}$. We performed a thoracotomy in the left fourth intercostal space and inserted polyvinyl catheters (inside diameter, $0.10 \mathrm{~cm}$; outside diameter, $0.15 \mathrm{~cm}$ ) into the ascending thoracic aorta through the left internal thoracic artery, and into the left atrium. Postoperative care was given as described previously (13).

Experimental protocols. All the newborn lambs were conscious, ambulatory, and vigorously feeding from their ewe within $24 \mathrm{~h}$ after surgery. Studies were performed $72 \mathrm{~h}$ after surgery. At that time, we blindfolded the lambs, placed them in a nylon mesh sling, and began a continuous recording of heart rate and aortic blood pressure. After the lambs had been resting quietly for $30 \mathrm{~min}$, we withdrew $0.5 \mathrm{ml}$ of aortic blood for measurement of oxygen saturation, hemoglobin concentration, $\mathrm{PO}_{2}, \mathrm{pH}$, and $\mathrm{PCO}_{2}$. Immediately after obtaining the blood sample, we measured regional blood flow by injecting $15-\mu \mathrm{m}$ diameter radionuclide-labeled microspheres (Co-57, In-114m, Sn-113, Sr-85, $\mathrm{N}_{\mathrm{b}}-95$, or Sc-46) into the left atrium while withdrawing a reference blood sample from the ascending aorta for $2 \mathrm{~min}$ at $4 \mathrm{ml} /$ min. Each injection consisted of 1.5-2 $\times 10^{6}$ microspheres given over $30 \mathrm{sec}$. There were no changes in heart rate or blood pressure during the injections of microspheres. All of the measurements were performed using techniques that have been described previously $(1,13,19)$.

A vented transparent polyethylene bag was then placed over the lamb's head and a gas mixture containing a reduced oxygen concentration within nitrogen was administered at a rate of 25 30 liters $/ \mathrm{min} ; 2-5 \%$ carbon dioxide was given as needed to prevent a compensatory reduction in $\mathrm{PCO}_{2}$ and to maintain the arterial $\mathrm{PCO}_{2}$ at 30-45 torr. We repeated the measurements of aortic blood oxygen saturation, hemoglobin concentration, $\mathrm{PO}_{2}$, $\mathrm{pH}, \mathrm{PCO}_{2}$, and regional myocardial blood flows at the end of two separate 20 -min periods of hypoxemia which were produced by the administration of environmental concentrations of $8-10 \%$ and $5-6 \%$ oxygen; in each lamb, we attempted to reduce aortic blood oxygen content by 50 and $75 \%$, respectively. This duration of hypoxemia was used because initial experience indicated that the lambs would develop a metabolic acidemia after more than $20 \mathrm{~min}$ in an oxygen concentration of $5-6 \%$. Each lamb was studied in the same order: control, $8-10 \%$ oxygen, and $5-6 \%$ oxygen. There was no recovery period in between the periods of hypoxemia. Using the above protocol, a single study was performed in each lamb. The lambs were sacrificed after the experiment was completed, and we verified correct placement of the catheters at necropsy.

Measurements and calculations. All values for $\mathrm{PO}_{2}$ were corrected to the body temperature of sheep, $39^{\circ} \mathrm{C}(25)$. Blood oxygen content ( $\mathrm{mmol} /$ liter) was calculated from the measurements of blood oxygen saturation and hemoglobin concentration by using the constants of $22.4 \mathrm{ml} \mathrm{O} / 2 / \mathrm{mmol}$ and $1.36 \mathrm{ml}$ oxygen $/ \mathrm{g}$ hemoglobin (25).

After the final measurement was made, the lamb was killed, the correct placement of each catheter was verified, and the heart and brain were removed for blood flow analysis. The heart was trimmed free of epicardial fat and great vessels, weighed (Mettler P1200), perfused with $8 \%$ formaldehyde, and divided into 12 segments. After the atria were separated from the ventricular myocardium along the atrioventricular groove, the right and left ventricular free walls were separated from the ventricular septum (16). After separation from the chordae tendinae, the distal 3 $\mathrm{mm}$ of the left and right ventricular papillary muscles were removed, sectioned, grossly examined, and counted separately. Using a tissue slicer blade (A. H. Thomas 6727-C20), we then divided the right and left ventricular free walls into inner, middle, and outer segments and sectioned the ventricular septum into right, middle, and left segments. Each region of myocardium was weighed and adjusted back to its preformaldehyde perfusion weight as previously described (16). We counted the radioactivity of each myocardial region and cerebral hemisphere separately with a sodium iodide crystal and well counter (Tracor Analytic
Co., Elk Grove, IL) and a 1000-channel pulse height analyzer (Ultima II, Norlund Corp., Ft. Atkinson, WI). Blood flow was calculated with a computer program using least squares analysis of the spectra (1). Based on an independent measurement of counts per microsphere, we calculated that at least 400 microspheres were present in each tissue sample. This provides a statistical accuracy of $\pm 10 \%$ (5). Adequate mixing of microspheres within the circulation was demonstrated by showing that blood flow to each cerebral hemisphere $(\mathrm{ml} / \mathrm{min} / \mathrm{g}$ of tissue) was within $10 \%$ of its pair (19).

We manually withdrew $6 \mathrm{ml}$ of blood from the coronary sinus of three lambs during and for 2 min after the left atrial injection of the microspheres. Because there was no greater than background radioactivity in the blood samples that were obtained during control periods and during both levels of hypoxemia, we conclude that there was no myocardial shunting of the $15-\mu \mathrm{m}$ diameter microspheres.

The mean \pm standard error was calculated for each variable. We performed linear regression analyses (22) for the control period and for the data obtained during hypoxemia. The slope of each regression line was tested against a slope of zero and the slopes of the two regression lines were compared with small sample $t$ tests for parallelism (22). Significance was placed at the $P=0.05$ level. When it was necessary to compare both hypoxemic groups to the control values (Tables 1 and 3), we performed two sets of paired $t$ tests and used the Bonferroni adjustment to decrease the $P$ value of significance to 0.025 .

\section{RESULTS}

The control measurements (Table 1) for arterial blood gasses, hemoglobin concentration, heart rate, and mean blood pressure were similar to previous measurements in conscious newborn lambs $(2,15)$. During the control period, each of the lambs had an arterial blood oxygen tension greater than 70 torr and an oxygen saturation greater than $93 \%$. The variability in control aortic blood oxygen contents was related almost entirely to differences in hemoglobin concentrations. Our protocol produced significant reductions in arterial $\mathrm{PO}_{2}$ without any significant change in $\mathrm{pH}$ or $\mathrm{PCO}_{2}$ (Table 1). The average reduction in arterial blood oxygen content was $52 \%$ during the administration of $8-10 \%$ oxygen and $75 \%$ during $5-6 \%$ oxygen. Heart rate and hemoglobin concentration increased significantly during hypoxemia, but there was no change in aortic mean blood pressure (Table 1).

In agreement with a previous study, we noted regional differences in myocardial blood flow during the control period wherein left ventricular flow is greater, right ventricular flow is smaller, and ventricular septal flow is intermediate (16). In the present study, blood flow within any region was not related to aortic blood oxygen content during the control period (Figs. 1 and 2). During hypoxemia, there were significant linear increases in

Table 1. Measurements in 10 conscious lambs*

\begin{tabular}{lccc}
\cline { 3 - 4 } & Control & $8-10 \% \mathrm{O}_{2}$ & $5-6 \% \mathrm{O}_{2}$ \\
\hline Aortic & & & \\
$\quad \mathrm{PO}_{2}$ (torr) & $78 \pm 2$ & $25 \pm 2 \dagger$ & $16 \pm 2 \dagger$ \\
$\mathrm{pH}$ (units) & $7.43 \pm 0.02$ & $7.41 \pm 0.02$ & $7.37 \pm 0.03$ \\
$\mathrm{PCO}_{2}$ (torr) & $39 \pm 2$ & $37 \pm 2$ & $35 \pm 3$ \\
$\mathrm{O}_{2}$ content $(\mathrm{mmol} / \mathrm{liter})$ & $6.3 \pm 0.3$ & $3.0 \pm 0.2 \dagger$ & $1.5 \pm 0.2 \dagger$ \\
$\quad$ Hemoglobin $(\mathrm{g} / \mathrm{dl})$ & $10.3 \pm 0.3$ & $10.8 \pm 0.4$ & $1.8 \pm 0.4 \dagger$ \\
Heart rate (beats/min) & $189 \pm 11$ & $262 \pm 16 \dagger$ & $256 \pm 19 \dagger$ \\
Aortic mean blood & $68 \pm 3$ & $65 \pm 4$ & $63 \pm 5$ \\
$\quad$ pressure $(\mathrm{mm} \mathrm{Hg})$ & & & \\
\hline
\end{tabular}

* Values are expressed as mean \pm SE. $8-10 \% \mathrm{O}_{2}$ and $5-6 \% \mathrm{O}_{2}$ indicate data obtained during when the lambs were in these concentrations of environmental oxygen, respectively. $\dagger, P<0.025$, compared with control values. 

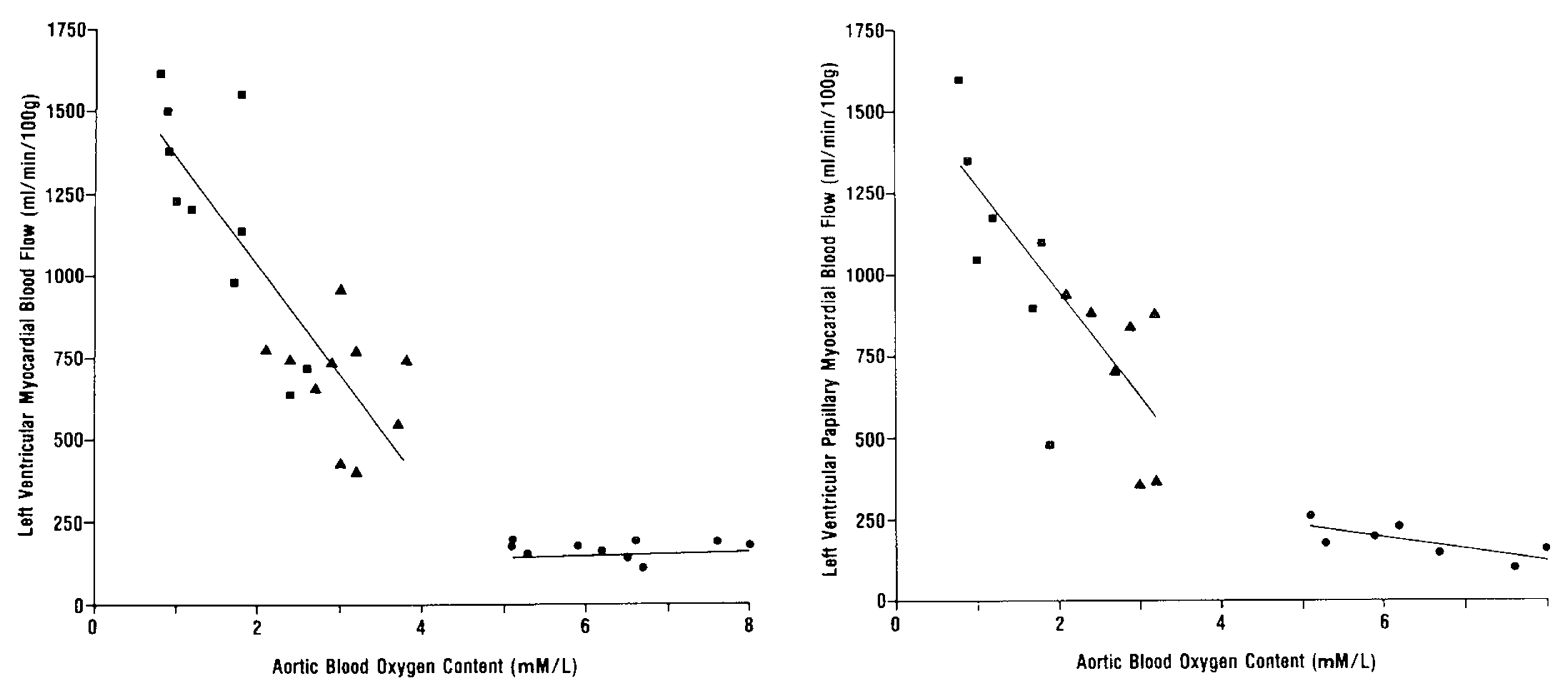

Fig. 1. The relationship between arterial blood oxygen content and blood flow to the left ventricular free wall and the papillary muscle of the left ventricle. $\boldsymbol{\bullet}, \mathbf{\Lambda}$, and $\mathbf{\square}$ represent data points during the control period, $8-10 \%$ oxygen and 5-6\% oxygen, respectively.
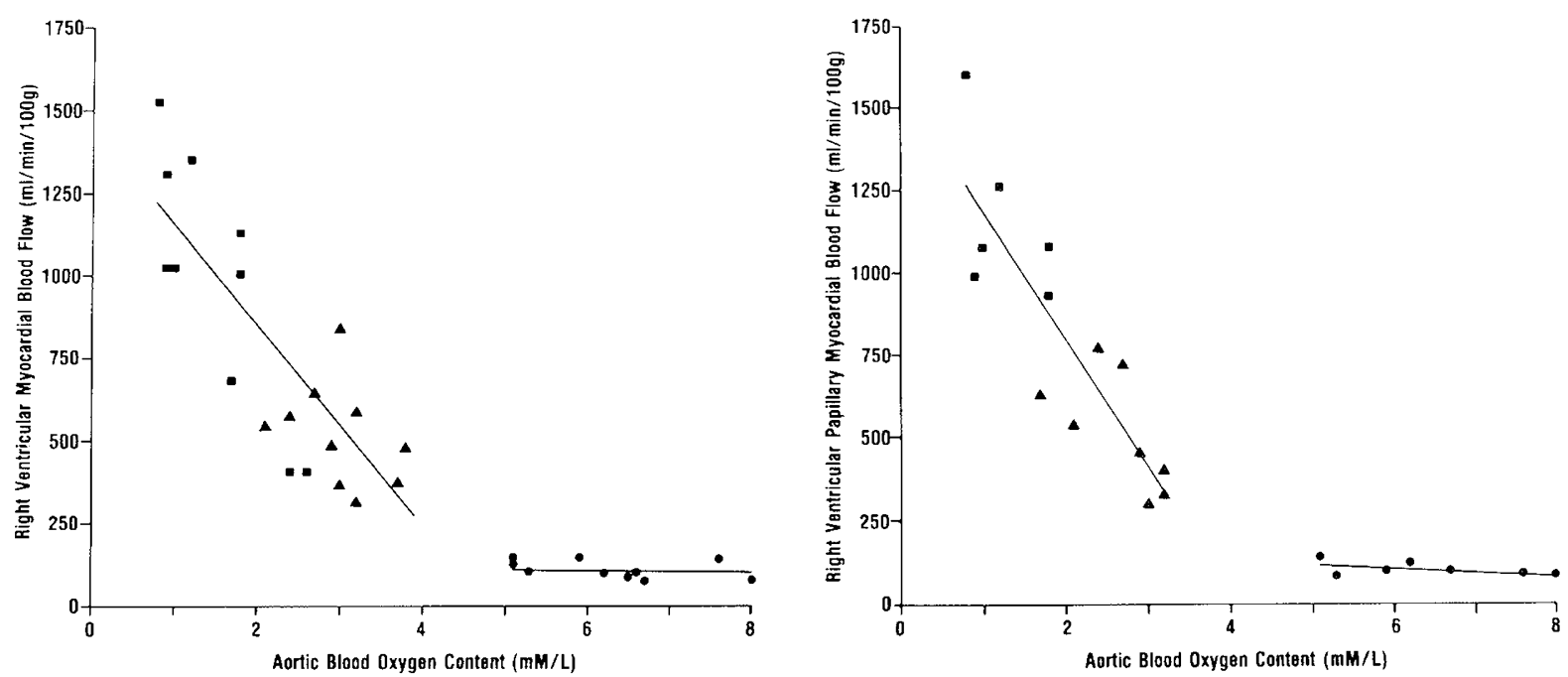

Fig. 2. The relationship between arterial blood oxygen content and blood flow to the right ventricular free wall and the papillary muscle of the right ventricle. $\bullet, \mathbf{\Lambda}$, and $\mathbf{\square}$ represent data points during the control period and 8-10\% oxygen and 5-6\% oxygen, respectively.

Table 2. Relationships between aortic blood oxygen content and regional myocardial blood flows during hypoxemia*

\begin{tabular}{llc}
\hline Region & $\begin{array}{c}\text { Regression } \\
\text { equation }\end{array}$ & $\begin{array}{c}\text { Correlation } \\
\text { coefficient }\end{array}$ \\
\hline LV & $y=-325 x+1666 \dagger$ & -0.83 \\
LV pap & $y=-322 x+1593 \dagger$ & -0.84 \\
RV & $y=-322 x+1479 \dagger$ & -0.83 \\
RV pap & $y=-377 x+1524 \dagger$ & -0.80 \\
Septum & $y=-294 x+1485 \dagger$ & -0.84 \\
Atria & $y=-131 x+697 \dagger \ddagger$ & -0.66 \\
\hline
\end{tabular}

* LV and RV, myocardium of the left and right ventricular free walls respectively. LV pap and RV pap, papillary muscles of the left and right ventricles, respectively. Equations are from linear regression analysis which was performed with the data during hypoxemia. $\dagger$, significantly different from slope $=0$ and the slope of the regression equation for the control data. $\ddagger$, significantly different from slopes of all other hypoxemic regression lines. $n=10$ for $\mathrm{LV}, \mathrm{RV}$, septum, and atria; $n=7$ for $\mathrm{LV}$ pap and RV pap. myocardial blood flow in each myocardial region (Figs. 1 and 2 and Table 2). As estimated by the slope of the regression lines, the magnitude of the flow increases were similar for each region of ventricular myocardium, but the slope was less steep in the atria (Table 2). None of the linear regression equations were improved by fitting a quadratic function. There was no significant change in the inner-to-outer ratios of blood flow in the left or right ventricular free walls during hypoxemia, but the ratio of blood flow to the right and left septal myocardium increased significantly (Table 3 ). Oxygen delivery increased in each region of myocardium during hypoxemia, with the highest values occurring during the milder degrees of hypoxemia (Table 3 ). However, aortic blood oxygen content and oxygen delivery were not significantly related in a linear or quadratic fashion in any region of the heart.

\section{DISCUSSION}

Several reports have demonstrated that myocardial dysfunction may occur in human newborns in conjunction with severe 
Table 3. Regional transmural blood flow ratios and oxygen deliveries in 10 conscious lambs*

\begin{tabular}{lccc}
\hline & Control & $8-10 \% \mathrm{O}_{2}$ & $5-6 \% \mathrm{O}_{2}$ \\
\hline Blood flow ratios & & & \\
LV I:O & $1.17 \pm 0.06$ & $1.09 \pm 0.05$ & $1.10 \pm 0.05$ \\
RV I:O & $1.17 \pm 0.05$ & $1.11 \pm 0.06$ & $1.14 \pm 0.06$ \\
Sep R:L & $0.73 \pm 0.05$ & $0.89 \pm 0.05$ & $1.00 \pm 0.04 \dagger$ \\
Oxygen deliveries & & & \\
LV & $1067 \pm 44$ & $2004 \pm 184 \dagger$ & $1638 \pm 152 \dagger$ \\
RV & $639 \pm 53$ & $1540 \pm 146 \dagger$ & $1317 \pm 118 \dagger$ \\
Septum & $961 \pm 80$ & $1774 \pm 164 \dagger$ & $1423 \pm 120 \dagger$ \\
Atria & $637 \pm 54$ & $858 \pm 63 \dagger$ & $729 \pm 73$ \\
LV pap & $1135 \pm 40$ & $1932 \pm 136 \dagger$ & $1440 \pm 115 \dagger$ \\
RV pap & $652 \pm 46$ & $1351 \pm 152 \dagger$ & $1196 \pm 168 \dagger$ \\
\hline
\end{tabular}

$*$ Values are expressed as mean \pm SE. Oxygen deliveries are in $\mu \mathrm{mol} /$ $\mathrm{min} / 100 \mathrm{~g}$. LV and RV, myocardium of the left and right ventricular free walls, respectively. I:O, ratio of blood flow to inner and outer myocardial layers. Sep $R: L$, ratio of blood flow to layers of right and left septal myocardium. LV pap and RV pap, papillary muscles of the respective ventricles. $8-10 \% \quad \mathrm{O}_{2}$ and $5-6 \% \quad \mathrm{O}_{2}$ indicate data obtained when the lambs were in these concentrations of environmental oxygen, respectively. $\dagger, P<0.025$, compared with control values. $n=10$ for blood flow ratios and regional oxygen deliveries, except for $n=7$ for LV pap and RV pap.

birth asphyxia $(4,33,34)$. The demonstration of electrocardiographic Q or ST-T wave abnormalities, increased creatine phosphokinase $\mathrm{MB}$ activity, and decreased myocardial uptake of thallium-201 in survivors of birth asphyxia suggests an ischemic basis for the myocardial dysfunction $(4,12,28,34)$. Further support for this concept was found in the demonstration of subendocardial or papillary muscle infarction in either ventricle in newborns who did not survive birth asphyxia $(4,9,33,39)$. Ischemia has been strongly implicated in the pathophysiology of the myocardial dysfunction of birth asphyxia yet necropsy evidence has demonstrated normal patency of the coronary arteries $(6,9,21,33,37)$.

Some investigators have suggested that the myocardial ischemia of birth asphyxia may be the result of the simultaneously occuring hypoxemia, with or without additional stresses such as hypoglycemia $(4,21,30)$. In contrast, several pieces of experimental evidence suggest that hypoxemia alone does not cause left ventricular myocardial ischemia, hypoxia, or dysfunction in vivo. Hypoxemia is associated with increased myocardial blood flow and no change in oxygen consumption in the left ventricular free wall in fetal lambs (14). Furthermore, blood flow and oxygen consumption in the left ventricular free wall increased during hypoxemia in newborn lambs $(13,24)$. Similarly, left ventricular myocardial blood flow increased and myocardial oxygen consumption was not diminished during isolated hypoxemia in adult humans and dogs $(17,18)$. Although it is not possible currently to measure oxygen consumption in each region of the heart, the present study demonstrates that decreases in $\mathrm{PO}_{2}$ as low as $12-$ 15 torr are associated with increases in blood flows and oxygen deliveries in the right and left ventricular papillary muscles as well as in the right and left ventricular free walls in lambs. In theory, it would be anticipated that more severe degrees of hypoxemia could exhaust the coronary vasodilator reserve capacity and produce subendocardial ischemia due to an imbalance between oxygen supply and demand. However, more severe degrees of isolated hypoxemia are not sustained as isolated phenomena in vivo. A metabolic acidemia occurs quickly, which appears to be related to the severe reductions in blood flow to the gastrointestinal tract, kidneys, and carcass (38). As the complicating acidemia has its own depressant effects on myocardial blood flow and function, it is apparent that unless there is significant species variability, hypoxemia alone is unlikely to be the cause of the subendocardial or papillary muscle ischemia and the resultant myocardial dysfunction that may occur in conjunction with severe birth asphyxia.

It has been suggested that the myocardial ischemia of birth asphyxia may be related to an increase in cardiac work which occurs during hypoxemia pulmonary vasoconstriction $(30,34)$. This could account for the greater frequency of right ventricular ischemia but it is unlikely to account for the occurrence of left ventricular ischemia. It may be noteworthy that the degree of pulmonary vasoconstriction produced with the model used in this study is considerably less than that which can occur during birth asphyxia $(4,38)$.

The increases in regional myocardial oxygen deliveries in this study (Table 3 ) and in left ventricular myocardial oxygen consumption in previous studies $(13,24)$ during moderate hypoxemia in newborn lambs are intriguing. If the increases in regional myocardial blood flows during hypoxemia had occurred solely in order to maintain myocardial oxygen consumption, then we would not have expected regional myocardial deliveries and left ventricular myocardial oxygen consumption to increase beyond control levels. We did not measure left or right ventricular work in this study, but information from previous studies suggests that at least some of the increases in oxygen deliveries and consumptions may have resulted from simultaneous increases in left and right ventricular work $(32,38)$. However, left ventricular myocardial oxygen consumption increased during hypoxemia in lambs even when cardiac work was kept constant (24). Lee et al. (24) have suggested that another possible reason for the increases in regional oxygen deliveries/consumption may be a shift toward the use of less efficient myocardial metabolic pathways. This could be mediated by the oxygen wasting effect of an increase in circulating catecholamine concentrations; this appears to induce lipolysis, thereby resulting in increased arterial free fatty acid concentration as well as increased myocardial oxygen and free fatty acid consumption $(23,26,27,39)$. Although these mechanisms have been demonstrated only in mature subjects, significant increases in arterial concentrations of free fatty acids and catecholamines have been demonstrated during hypoxemia in lambs $(8,20,31)$.

Available information has demonstrated that coronary blood flow is closely related to aortic blood oxygen content during hypoxemia in fetuses, newborns, and adults of several species but the mechanism(s) have not been determined $(13,14,17,18$, $24,29)$. Some potential mediators of increased myocardial blood flow during hypoxemia include oxygen itself, the sympathetic nervous system, and adenosine. The demonstration of increased myocardial blood flow during hypoxemia in the presence of $\beta$ blockade in lambs suggests that increased sympathetic tone is not a major mediator (24). Adenosine is a potent coronary vasodilator in newborn lambs and adult dogs, but the role of adenosine as the mediator of hypoxemic coronary vasodilation remains controversial $(3,10,11,35,36)$. It is possible that oxygen availability mediates the coronary vasodilation directly. Further investigation will be necessary to determine the mediator(s) of hypoxemic coronary vasodilation.

\section{REFERENCES AND NOTES}

1. Baer RW, Verrier ED, Vlahakes GJ, Payne BD, Hoffman JIE 1980 Validation of eight sequential myocardial blood flow determinations with radioactive microspheres using least-squares analysis. Circulation 62(Suppl III)P:65 (abstr)

2. Berman W Jr, Musselman J, Shortencarrier R 1980 The physiologic effect sof digoxin under steady-state drug conditions in newborn and adult sheep.
Circulation $62: 1165$

3. Berne RM 1963 Cardiac nucleotides in hypoxia: possible role in regulation of coronary blood flow. Am J Physiol 204:317

4. Bucciarelli RL, Nelson RM, Eagan EA Jr, Eitzman DV, Gessner IH 1977 Transient tricuspid insufficiency of the newborn: a form of myocardial dysfunction in stressed newborns. Pediatrics 59:330 
5. Buckberg GD, Luck JC, Payne BD, Hoffman JIE, Fixler DE 1971 Some sources of error in measuring regional blood flow with radioactive microspheres. J Appl Physiol 31:598

6. Burnard ED, James LS 1961 Failure of the heart due to undue asphyxia at birth. Pediatrics 28:545

7. Cabal LA, Devaskar V, Siassi B, Hodgman JE, Emmanuoilides G 1980 Cardiogenic shock associated with perinatal asphyxia in perterm infants. J Pediatr 96:705

8. Comline RS. Silver M 1961 The release of adrenaline and noradrenaline from the adrenal glands of the fetal sheep. J Physiol (Lond) 156:424

9. Donnelly WH, Bucciarelli RL, Nelson RM 1980 Ischemic papillary muscle necrosis in stressed newborn infants. J Pediatr 96:295

10. Downey HF, Crystal GJ, Bockman EL, Bashour FA 1982 Nonischemic myo cardial hypoxia: coronary dilation without increased tissue adenosine. Am J Physiol 243:H512

11. Downing SE Lee JC Weinstein EM 1982 Coronary dilator actions of adenosine and carbon dioxide in experimental diabetes. Am J Physiol 243:H252

12. Finley JP, Howman-Giles RB, Gilday DL, Bloom KR, Rowe RD 1979 Transient myocardial ischemia of the newborn infant demonstrated by thallium myocardial imaging. J Pediatr 94:263

13. Fisher DJ 1983 Left ventricular oxygen consumption and function in hypoxemia in conscious lambs. Am J Physiol 244:H664

14. Fisher DJ, Heymann MA, Rudolph AM 1982 Fetal myocardial oxygen and carbohydrate consumption during acutely induced hypoxemia. Am J Physio 242: $\mathrm{H} 657$

15. Fisher DJ, Heymann MA, Rudolph AM 1981 Myocardial consumption of oxygen and carbohydrates in newborn sheep. Pediatr Res 15:843

16. Fisher DJ, Heymann MA, Rudolph AM 1982 Regional myocardial blood flow and oxygen delivery in fetal, newborn and adult sheep. Am J Physio 243:H729

17. Hackel DB, Goodale WT, Kleinerman J 1954 Effects of hypoxia on the myocardial metabolism of intact dogs. Circ Res 2:169

18. Hellems HK Ord JW Almers FN, Christensen RC 1957 Effect of hypoxia on coronary blood flow and myocardial metabolism in normal human subjects. Circulation 16:893 (abstr)

19. Heymann MA. Payne BD. Hoffman JIE, Rudolph AM 1977 Blood flow measurements with radionuclide-labeled microspheres. Prog Cardiovasc Dis $20: 55$

20. Jones CT 1977 The development of some metabolic responses to hypoxia in the fetal sheep. J Physiol (Lond) 265:743

21. Killbride H, Way GL, Merenstein GB, Winfield JM 1980 Myocardial infarction in the neonate with normal heart and coronary arteries. Am $J$ Dis Child 134:759

22. Kleinbaum DG, Kupper LL 1978 Applied Regression Analysis and Other Multivariable Methods. North Scituate, MA. Dixbury Press

23. Klocke FJ. Kaiser GA, Ross J Jr, Braunwald E 1965 Mechanism of increased myocardial oxygen uptake produced by catecholamines. Am J Physiol 209:913

24. Lee JC, Halloran KH. Taylor JFN, Downing SE 1973 Coronary flow and myocardial metabolism in newborn lambs: effects of hypoxia and acidemia.
Am J Physiol 224:1381

25. Lister G, Walter TK Vermold HT, Dallman PR, Rudolph AM 1979 Oxygen delivery in lambs: cardiovascular and hematologic development. Am J Physiol 237:H668

26. Mjos OD 1971 Effect of free fatty acids on myocardial function and oxygen consumption in intact dogs. J Clin Invest 50:1386

27. Mjos OD 1966 Effect of free fatty acids on myocardial function and oxygen consumption of the perfused rat heart. Am J Physiol 210:280

28. Nelson RN, Bucciarelli RL, Eitzman EV, Egan EA, Gessner IH 1978 Serum creatine phosphokinase MB fraction in newborns with transient tricuspid insufficiency. N Engl J Med 298:146

29. Peeters LLH, Sheldon RE, Jones MD Jr, Makowski EL, Meschia G 1979 Blood flow in fetal organs as a function of arterial oxygen content. Am $\mathbf{J}$ Obstet Gynecol 135:637

30. Riemenschneider TA, Nielsen HC, Ruttenberg HD, Jaffe RB 1976 Disturbances of the transitional circulation: spectrum of pulmonary hypertension and myocardial dysfunction. J Pediatr 89:622

31. Robinson JS, Jones CT, Thorburn GD 1978 The effects of hypoxemia in fetal sheep. J Clin Pathol (R Coll Pathol) 11:(Suppl 30)127

32. Rooke GA, Feigl EO 1982 Work as a correlate of canine left ventricular oxygen consumption and the problem of catecholamine oxygen wasting. Circ Res $50: 273$

33. Rowe RK, Hoffman T 1972 Transient myocardial ischemia of the newborn infant: a form of severe cardiorespiratory distress in full-term infants. J Pediat $81: 243$

34. Rowe RD, Izukawa T, Mulholland HC, Bloom KR, Cook DH, Swyer PR 1978 Nonstructural heart disease in the newborn. Arch Dis Child 53:726

35. Rubio R, Weidmeir VT, Berne RM 1974 Relationship between coronary blood flow and adenosine production and release. J Mol Cell Cardiol 6:561

36. Schrader J, Haddy FJ, Gerlach E 1977 Release of adenosine, inosine and hypoxanthine during hypoxia, flow-autoregulation and reactive hypoxemia Pfleugers Arch 369:1

37. Setzer E, Ermocilla R, Tonkin I, John E, Samsa M, Cassidy G 1980 Papillary muscle necrosis in a neonatal autopsy population: incidence and associated clinical manifestations. J Pediatr 96:289

38. Sidi D, Kuipers JRB, Heymann MA, Rudolph AM 1983 Effects of ambient temperature on oxygen consumption and the circulation in newborn lambs at rest and during hypoxemia. Pediatr Res 17:254

39. Simonsen S, Kjekshus JK 1978 The effect of free fatty acids on myocardial oxygen consumption during atrial pacing and catecholamine infusion in man. Circulation 58:484

40. Supported by a grant from The American Heart Association, Texas Affiliate Inc.

41. Requests for reprints should be addressed to: David J. Fisher, M.D., The University of Texas Medical School at Houston, Department of Pediatrics. P. Box 20708, Houston, TX 77025.

42. The authors thank Dr. Robert Bigelow for his guidance in the statistical analysis and Ms. Jody Uran for her secretarial assistance.

43. Received for publication August 19, 1983.

44. Accepted for publication February 29, 1984 